\title{
Analisis Kesesuaian Kualitas Air Sungai dengan Baku Mutu Air untuk Budidaya Ikan Air Tawar di Kabupaten Tabalong
}

\author{
Noor Zam Zammi ${ }^{1}$, Rezky Nur Astriyani' ${ }^{2}$, Suharianto ${ }^{3}$ \\ ${ }^{1}$ Departement of Urban and Regional Planning, Civil and Planning Engineering, Institut Teknologi Kalimantan, \\ Balikpapan. Email: 08161054@student.itk.ac.id \\ ${ }^{2}$ Departement of Urban and Regional Planning, Civil and Planning Engineering, Institut Teknologi Kalimantan, \\ Balikpapan. Email: 08161066@student.itk.ac.id \\ ${ }^{3}$ Departement of Urban and Regional Planning, Civil and Planning Engineering, Institut Teknologi Kalimantan, \\ Balikpapan. Email: 08161082@ student.itk.ac.id
}

\begin{abstract}
The Minapolitan area in Tabalong District is one of the predominant areas from the point of economic interest based on Tabalong District's Urban Land Use Plan 2014-2034. The Minapolitan is the conception of fisheries economic development which it functions is in economy that consists of production, processing, and marketing the fisheries commodity, services, and other supporting activities. The fishery activities in Tabalong District are occurring mostly in Tabalong and Pemayaran River. The purpose of this research is to acknowledge the compatibility of water quality conditions based on water temperature, brightness, dissolved oxygen (DO), acidity level $(\mathrm{pH})$, ammonia $\left(\mathrm{NH}_{3}\right)$, and nitrite $\left(\mathrm{NO}_{2}\right)$. The data analysis instrument is using descriptive through comparison of the current water quality condition upon the water quality standard of freshwater fisheries. The result shows that the water quality in Sungai Tabalong and Sungai Pemayaran consecutively for water temperature $28^{\circ} \mathrm{C}$ and $30^{\circ} \mathrm{C}$, brightness $28 \mathrm{~cm}$ and $26 \mathrm{~cm}$, dissolved oxygen (DO) $4,2 \mathrm{mg} / \mathrm{L}$ and $4 \mathrm{mg} / \mathrm{L}$, acidity level (pH) 7 , ammonia 3,33 mg/L and $0,25 \mathrm{mg} / \mathrm{L}$ and nitrite $<0,3 \mathrm{mg} / \mathrm{L}$. Overall the whole fish in the river of Tabalong District still could survive as well as the fisheries activities. However, controlling the activity around the river and the implementation of aquaculture technology is required to intensify the water quality.
\end{abstract}

Keywords: Minapolitan, Water-Quality, Water-Quality-Standard

\begin{abstract}
Abstrak
Kawasan minapolitan di Kabupaten Tabalong merupakan salah satu kawasan strategis yang ditinjau dari sudut kepentingan ekonomi berdasarkan RTRW Kabupaten Tabalong Tahun 2014 - 2034. Kawasan minapolitan adalah konsepsi pembangunan ekonomi perikanan berbasis kawasan dimana memiliki fungsi utama ekonomi yang terdiri dari sentra produksi, pengolahan, pemasaran komoditas perikanan, pelayanan jasa, dan kegiatan pendukung lainnya. Kegiatan perikanan di Kabupaten Tabalong terpusat di kedua sungai yaitu Sungai Tabalong dan Pemayaran. Penelitian ini bertujuan untuk mengetahui kesesuaian kondisi kualitas air sungai berdasarkan suhu, kecerahan, oksigen terlarut $(\mathrm{DO})$, derajat keasaman $(\mathrm{pH})$, amoniak $\left(\mathrm{NH}_{3}\right)$ dan nitrit $\left(\mathrm{NO}_{2}\right)$ untuk kegiatan budidaya ikan air tawar di Kabupaten Tabalong. Analisis data dilakukan secara deskriptif melalui komparasi antara kondisi eksisting kualitas air dengan baku mutu air. Didapatkan kondisi kualitas air pada Sungai Tabalong dan Sungai Pemayaran untuk suhu secara berturut-turut adalah sebesar $28^{\circ} \mathrm{C}$ dan $30^{\circ} \mathrm{C}$, kecerahan sebesar 28 $\mathrm{cm}$ dan $26 \mathrm{~cm}$, oksigen terlarut (DO) sebesar 4,2 mg/L dan $4 \mathrm{mg} / \mathrm{L}$, derajat keasaman (pH) sebesar 7 untuk keduanya, amoniak $\left(\mathrm{NH}_{3}\right)$ sebesar 3,33 mg/L dan 0,25 mg/L, dan nitrit $\left(\mathrm{NO}_{2}\right)$ untuk keduanya adalah sebesar <0,3 $\mathrm{mg} /$ L. Secara keseluruhan ikan-ikan yang berada di perairan sungai Kabupaten Tabalong seluruhnya masih dapat bertahan hidup dan kegiatan budidaya masih dapat dilakukan. Namun dibutuhkan upaya pengendalian kegiatan di area sungai dan penerapan teknologi aquaculture agar kualitas air dapat meningkat.
\end{abstract}

Kata Kunci: Minapolitan, Kualitas-Air, Baku-Mutu-Air.

\section{Pendahuluan}

Peraturan Daerah Kabupaten Tabalong Nomor 19 Tahun 2014 Tentang Rencana Tata Ruang Wilayah (RTRW) Kabupaten Tabalong Tahun 2014 - 2034 menyatakan bahwa Kabupaten Tabalong memiliki kawasan strategis dari sudut kepentingan ekonomi, dimana salah satunya adalah kawasan minapolitan. 


\section{Analisis Kesesuaian Kualitas Air Sungai dengan Baku Mutu Air untuk Budidaya Ikan Air Tawar di Kabupaten Tabalong}

Sesuai dengan Peraturan Menteri Nomor 12 Tahun 2010 Tentang Minapolitan, minapolitan didefinisikan sebagai konsepsi pembangunan ekonomi kelautan dan perikanan berbasis kawasan dimana memiliki fungsi utama ekonomi, yang terdiri dari sentra produksi, pengelolahan, pemasaran komoditas perikanan, pelayanan jasa, dan kegiatan pendukung lainnya. Kawasan peruntukan perikanan di Kabupaten Tabalong meliputi kawasan peruntukan perikanan tangkap dan perikanan budidaya, dimana kawasan minapolitan di Kabupaten Tabalong adalah perikanan air tawar yang dimana di Kabupaten Tabalong terdapat 2 sungai besar, yaitu Sungai Tabalong dan Sungai Pemayaran. Sungai-sungai ini merupakan tempat jenis budidaya keramba dengan jumlah produksi yang terus meningkat, dimana pada tahun 2018 berjumlah 6754,7 ton.

Berbicara tentang sungai tentunya berhubungan langsung dengan kualitas air, dimana kualitas air sungai dapat mempengaruhi hasil produksi perikanan karena setiap jenis ikan yang di budidayakan di keramba menggunakan perairan sungai yang berada di Kabupaten Tabalong. Komoditas perikanan budidaya keramba yang sudah umum di Kabupaten Tabalong adalah ikan mas, ikan nila, ikan patin, dan ikan lele. Dengan berbagai ragam jenis komoditas perikanan yang berada di Kabupaten Tabalong, sehingga dianggap perlu dilakukannya analisis terkait kualitas air sungai berdasarkan suhu, kecerahan, oksigen terlarut (DO), derajat keasaman $(\mathrm{pH})$, amoniak, dan nitrit. Agar dapat tercipta indakan-tindakan atau upaya teknis yang dapat dilakukan dalam proses pembudidayaan keramba di Kabupaten Tabalong, maka perlu dilakukan analisis kesesuaian kualitas air sungai dengan baku mutu kualitas air untuk budidaya ikan di Kabupaten Tabalong.

\section{Metodologi}

\subsection{Lokasi Penelitian}

Penelitian ini dilakukan pada sungai Sungai Tabalong dan Sungai Pemayaran di Kabupaten Tabalong. Kabupaten Tabalong adalah salah satu kabupaten yang berada di Provinsi Kalimantan Selatan dengan wilayah seluas 355.335 Ha. Secara administrasi Kabupaten Tabalong memiliki batas-batas di sebelah utara dan timur dengan Provinsi Kalimantan Timur, sebelah selatan dengan Kabupaten Balangan di Provinsi Kalimantan Selatan, dan sebelah barat dengan Provinsi Kalimantan Tengah. Terdapat total sebanyak 12 kecamatan yang berada di Kabupaten Tabalong yaitu Kecamatan Banua Lawas, Pugaan, Kelua, Muara Harus, Tanta, Tanjung, Murung Pudak, Haruai, Bintang Ara, Upau, Muara Uya, dan Jaro. Untuk dapat memperjelas, berikut ini ditampilkan peta administrasi Kabupaten Tabalong:

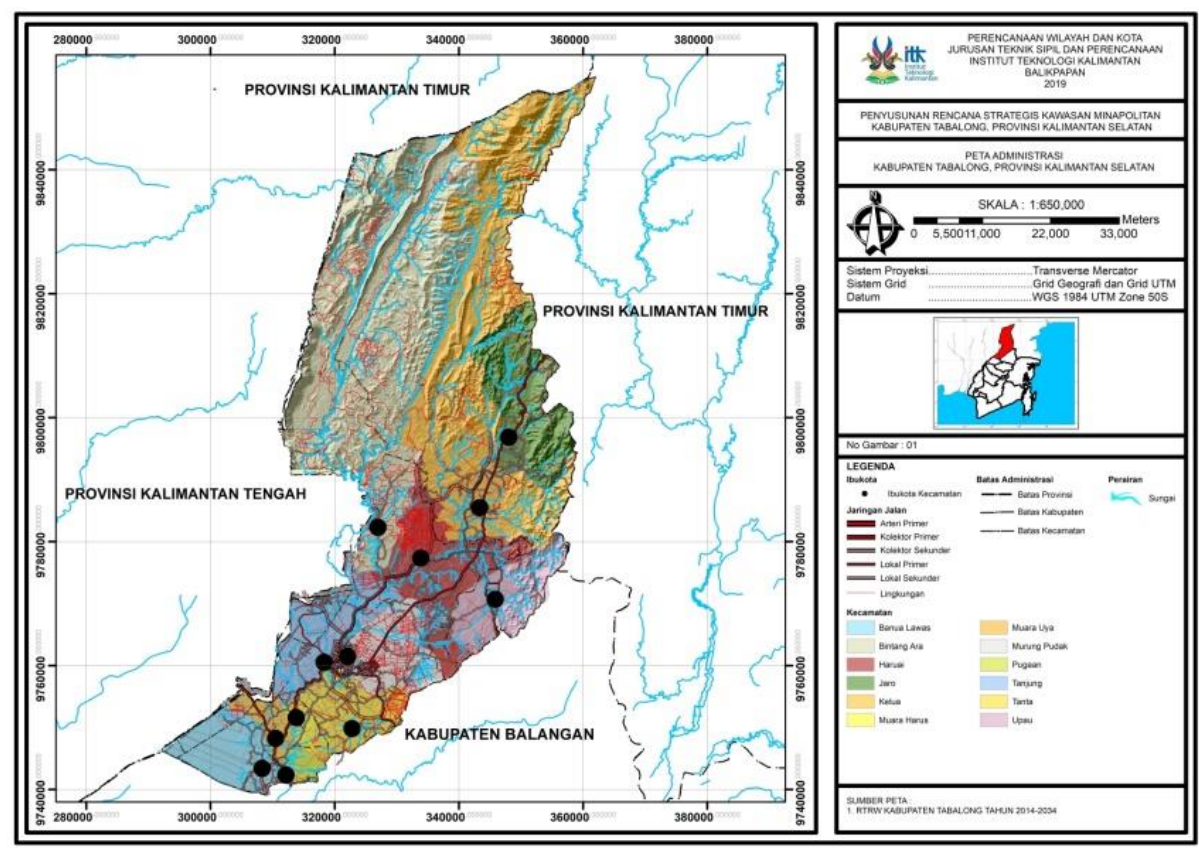

Gambar 1: Peta Batas Administrasi Kabupaten Tabalong

Sumber: RTRW Kabupaten Tabalong Tahun 2014-2034 


\section{Analisis Kesesuaian Kualitas Air Sungai dengan Baku Mutu Air untuk Budidaya Ikan Air Tawar di Kabupaten Tabalong}

Terdapat berbagai jenis penggunaan lahan di Kabupaten Tabalong, namun yang paling mendominasi adalah penggunaan lahan untuk kawasan tidak terbangun berupa hutan yaitu seluas 287.801,38 Ha. Berikut merupakan peta yang menunjukkan penggunaan lahan di Kabupaten Tabalong:

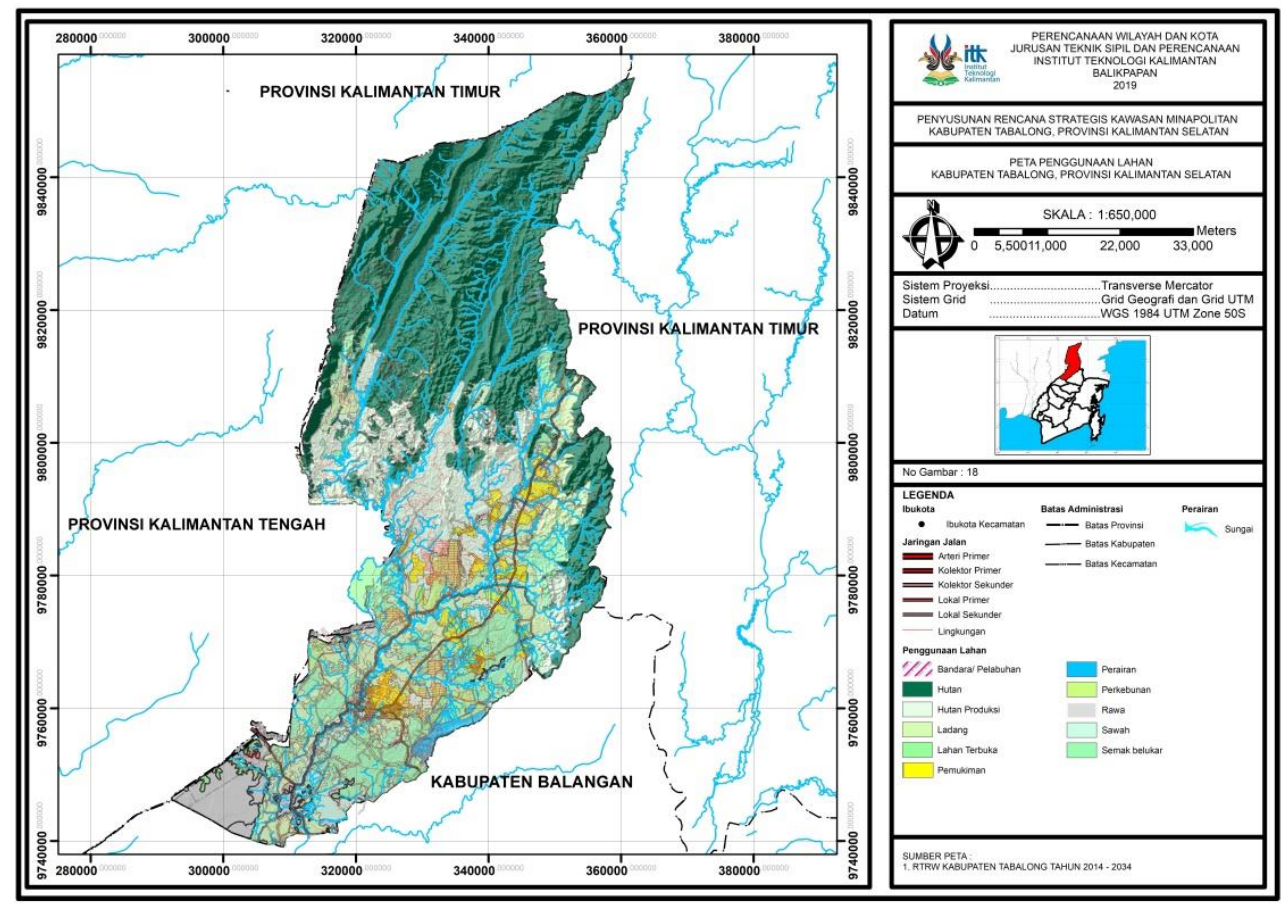

Gambar 2: Peta Penggunaan Lahan Kabupaten Tabalong Sumber: RTRW Kabupaten Tabalong Tahun 2014-2034

\subsection{Teknik Pengumpulan Data}

Dalam penelitian ini terdapat 2 jenis data yang digunakan yaitu data primer dan data sekunder. Data primer terkait permasalahan yang menyebabkan penurunan kualitas air pada sungai yang berada di Kabupaten Tabalong dan data sekunder terkait kondisi kualitas air pada sungai di Kabupaten Tabalong yang terdiri dari suhu, kecerahan, oksigen terlarut (DO), derajat keasaman $(\mathrm{pH})$, amoniak, dan nitrit serta jenis-jenis ikan yang sudah umum ditemui di Kabupaten Tabalong yaitu ikan mas, nila, patin, dan lele. Data primer dan data sekunder memiliki teknik pengumpulan data yang berbeda. Data primer dikumpulkan melalui survei primer dengan cara observasi dan wawancara. Sementara data sekunder dikumpulkan melalui survei sekunder (permohonan permintaan data) kepada instansi Badan Perencanaan dan Pembangunan Daerah (Bappeda) Kabupaten Tabalong dan Dinas Perikanan Kabupaten Tabalong.

\subsection{Teknik Analisis Data}

Analisis kualitas air sungai di Kabupaten Tabalong dilakukan dengan menggunakan analisis komparasi yaitu membandingkan antara kondisi eksisting kualitas air yang datanya diperoleh dari Dinas Perikanan Kabupaten Tabalong dengan standar baku mutu kualitas air yang dikeluarkan oleh Balai Besar Perikanan Air Tawar. Data-data terkait parameter baku mutu kualitas air yang digunakan oleh peneliti telah diperoleh dari Dinas Perikanan Kabupaten Tabalong, sehingga peneliti tidak melakukan pengambilan data terkait kondisi air secara langsung. Adapun standar yang digunakan adalah Baku Mutu Air untuk Budidaya Ikan, sebagai berikut: 
Analisis Kesesuaian Kualitas Air Sungai dengan Baku Mutu Air untuk Budidaya Ikan Air Tawar di Kabupaten Tabalong

Tabel 1: Standar Baku Mutu Kualitas Air

\begin{tabular}{lrcrrrr}
\hline \multirow{2}{*}{ Jenis Ikan } & \multicolumn{7}{c}{ Parameter } \\
\cline { 2 - 7 } & $\mathbf{S u h u}\left({ }^{\mathbf{0}} \mathbf{C}\right)$ & $\mathbf{p H}$ & $\mathbf{O}_{\mathbf{2}}(\mathbf{m g} / \mathbf{L})$ & $\begin{array}{c}\mathbf{N H}_{\mathbf{3}} \\
(\mathbf{m g} / \mathbf{L})\end{array}$ & $\mathbf{N O}_{\mathbf{2}}(\mathbf{m g} / \mathbf{L})$ & $\begin{array}{c}\text { Kecerahan } \\
(\mathbf{c m})\end{array}$ \\
\hline Mas & $25-30$ & $6,5-8,5$ & $>5$ & $<0,2$ & $<0,6$ & $10-30$ \\
Nila & $25-30$ & $6,5-8,5$ & $>5$ & $<0,2$ & $<0,6$ & $40-50$ \\
Lele & $25-30$ & $6,5-8,5$ & $>4$ & $<1$ & $<0,6$ & $25-35$ \\
Patin & $25-30$ & $6,5-8,5$ & $>5$ & $<0,01$ & $<1$ & $30-50$ \\
\hline & & & & Sumber: Baku Mutu Air untuk Budidaya Ikan, 2016
\end{tabular}

\section{Hasil dan Pembahasan}

\subsection{Faktor Kondisi Kualitas Air}

\subsubsection{Suhu}

Suhu merupakan ukuran atau derajat panas atau dinginnya suatu benda atau sistem. Suhu di definisikan sebagai suatu besaran fisika yang dimiliki bersama antara dua benda atau lebih yang berada dalam kesetimbangan termal (Putra, 2007). Dalam pengaruh secara perairan, pengaruh suhu permukaan sungai terhadap pertumbuhan fitoplankton secara tidak langsung akan mempengaruhi konsentrasi klorofil-a suatu perairan (Astrijaya, 2015).

\subsubsection{Derajat Keasaman $(p H)$}

Derajat keasaman $(\mathrm{pH})$ merupakan parameter penting dalam menentukan kualitas air. Nilai $\mathrm{pH}$ adalah gambaran jumlah atau aktivitas hidrogen dalam air. Secara umum, nilai $\mathrm{pH}$ menunjukkankan seberapa asam atau basa suatu perairan (Widigdo, 2001 dalam Yanti 2016).

\subsubsection{Oksigen Terlarut (DO)}

Parameter fisika-kimia air seperti konsentrasi oksigen terlarut (DO), suhu, dan total padatan tersuspensi (TSS), adalah beberapa parameter yang paling banyak mendapat perhatian karena mencerminkan kualitas air dan kesehatan suatu ekosistem perairan. Batas konsentrasi minimum serta peran DO bagi ekosistem perairan mencerminkan kemampuan badan air dalam menyesuaikan diri dengan kehadiran beban pencemar. DO sangat berpengaruh terhadap kehidupan ikan, terutama untuk pertumbuhan, memperbaiki jaringan dan reproduksi. (Sugianti, 2018).

\subsubsection{Amoniak $\left(\mathrm{NH}_{3}\right)$}

Amonia sangat beracun bagi hampir semua organisme karena ammonia dapat bersifat racun. Konsentrasi amonia yang tinggi dalam badan sungai mengindikasikan adanya pencemaran yang salah satunya disebabkan oleh buangan air limbah domestik baik segar (tidak terolah) maupun telah terolah, 49\% dari total pencemaran, (Halling-Sorensen \& Jorgensen, 1993 dalam Hibban 2016).

\subsubsection{Nitrit $\left(\mathrm{NO}_{2}\right)$}

Nitrit merupakan bentuk nitrogen yang hanya sebagian teroksidasi. Nitrit tidak ditemukan dalam air limbah yang segar, melainkan dalam limbah yang sudah basi atau lama. Nitrit tidak dapat bertahan lama dan merupakan keadaan sementara proses oksidasi antara amoniak dan nitrat. Nitrit bersumber dari bahanbahan yang bersifat korosif dan banyak dipergunakan di pabrik-pabrik. Nitrit tidak tetap dan dapat berubah menjadi amoniak atau dioksidasi menjadi nitrat (Ginting, 2007 dalam Emilia 2019).

\subsubsection{Kecerahan}

Kecerahan merupakan tingkat transparansi perairan yang dapat diamati secara visual menggunakan secchi disk. Dengan mengetahui kecerahan suatu perairan kita dapat mengetahui sampai dimana masih ada kemungkinan terjadi proses asimilasi dalam air, lapisan-lapisan mana yang tidak keruh, dan yang paling keruh. Perairan yang memiliki nilai kecerahan rendah pada waktu cuaca yang normal dapat memberikan suatu petunjuk atau indikasi banyaknya partikel-partikel tersuspensi dalam perairan tersebut. (Hamuna et al. 2018). Kecerahan merupakan salah satu faktor penting yang sangat berpengaruh 
Analisis Kesesuaian Kualitas Air Sungai dengan Baku Mutu Air untuk Budidaya Ikan Air Tawar di Kabupaten Tabalong

terhadap kelangsungan hidup mahluk laut yang membutuhkan cahaya matahari untuk proses fotosintesis. (Susiana, 2017).

\subsection{Pembahasan}

Wilayah perairan di Kabupaten Tabalong adalah perairan sungai yang mengalir di seluruh wilayah yang ada di Kabupaten Tabalong. Terdapat 2 sungai besar utama yang yaitu Sungai Tabalong dan Pemayaran dengan luasan sebagai berikut:

Tabel 2: Luas Sungai di Kabupaten Tabalong

\begin{tabular}{|c|c|}
\hline Nama Sungai & Luas (Ha) \\
\hline Sungai Tabalong & $1.393,37$ \\
\hline Sungai Pemayaran & 48,42 \\
\hline
\end{tabular}

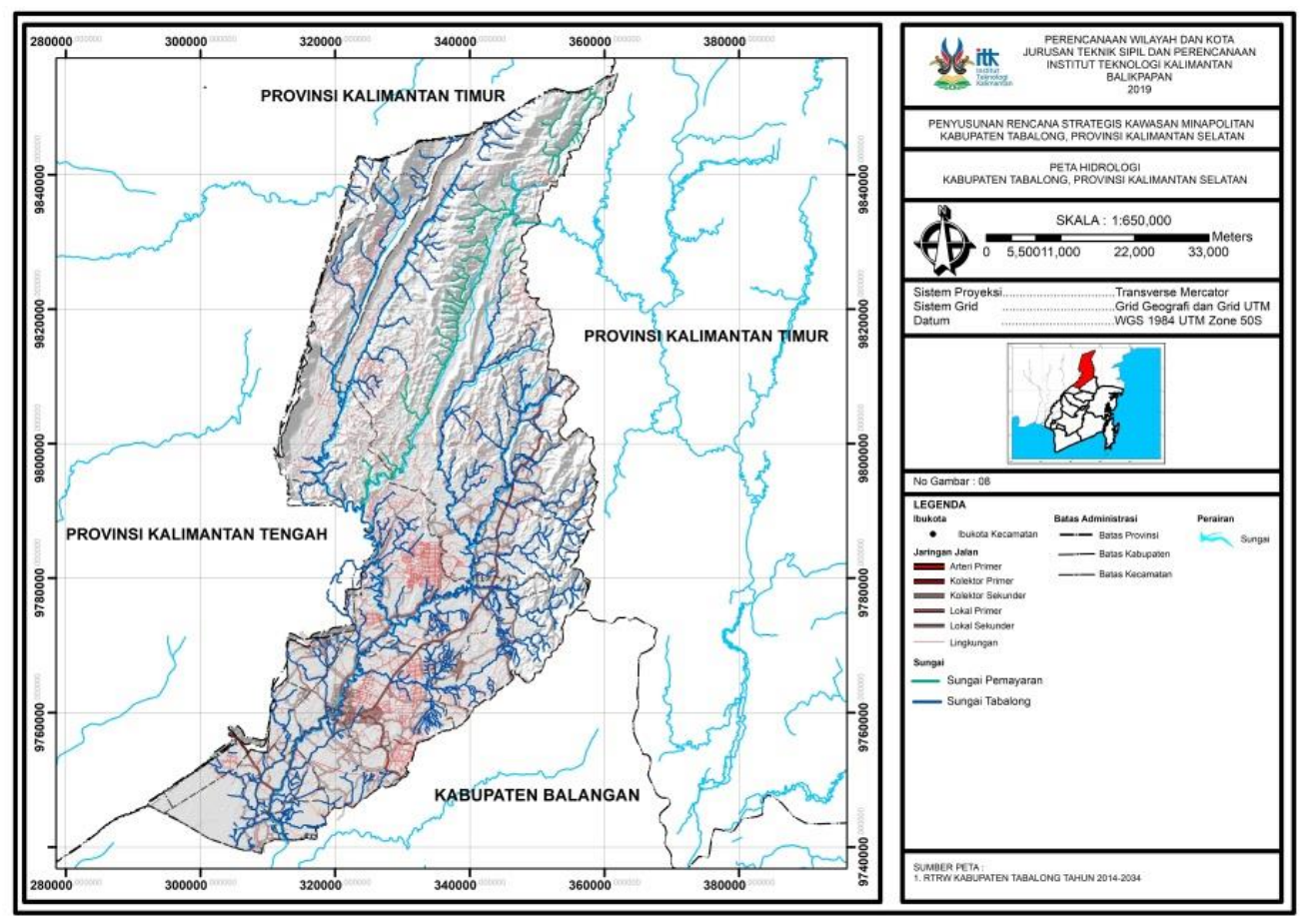

Gambar 3: Peta Hidrologi Kabupaten Tabalong

Sumber: RTRW Kabupaten Tabalong Tahun 2014-2034

Kondisi kualitas air di Sungai Tabalong dan Sungai Pemayaran di Kabupaten Tabalong yang diidentifikasi melalui suhu, kecerahan, oksigen terlarut (DO), derajat keasaman (pH), amoniak, dan nitrit, sehingga di dapatkan hasil sebagai berikut:

Tabel 3: Kondisi Kualitas Air Sungai di Kabupaten Tabalong

\begin{tabular}{lcrr}
\hline \multirow{2}{*}{ Kondisi Kualitas Air } & \multicolumn{2}{c}{ Nama Sungai } \\
\cline { 2 - 4 } & Sungai Tabalong & & Sungai Pemayaran \\
\hline Suhu $\left({ }^{\circ} \mathrm{C}\right)$ & 28 & 30 \\
Kecerahan $(\mathrm{cm})$ & 28 & 26 \\
Oksigen Terlarut $(\mathrm{DO})$ & 4,2 & 4 \\
$(\mathrm{mg} / \mathrm{L})$ & 7 & 7 \\
Derajat Keasaman $(\mathrm{pH})$ & 3,33 & 0,25 \\
Amoniak $\left(\mathrm{NH}_{3}\right)(\mathrm{mg} / \mathrm{L})$ & $<0,3$ & $<0,3$ \\
Nitrit $\left(\mathrm{NO}_{2}\right)(\mathrm{mg} / \mathrm{L})$ & Sumber: Dinas Perikanan Kabupaten Tabalong 2019
\end{tabular}




\section{Analisis Kesesuaian Kualitas Air Sungai dengan Baku Mutu Air untuk Budidaya Ikan Air}

Tawar di Kabupaten Tabalong

Setelah dilakukan identifikasi kondisi kualitas air di Kabupaten Tabalong, maka selanjutnya adalah melakukan perbandingan antara kondisi eksisting dan baku mutu kualitas air untuk perikanan budidaya, maka didapatkanlah hasil sebagai berikut:

Tabel 4: Perbandingan Kondisi Eksisting dan Baku Mutu Kualitas Air di Kabupaten Tabalong

\begin{tabular}{|c|c|c|c|c|c|c|}
\hline \multirow{2}{*}{$\begin{array}{c}\text { Kondisi } \\
\text { Kualitas } \\
\text { Air }\end{array}$} & \multicolumn{2}{|c|}{ Eksisting } & \multicolumn{4}{|c|}{ Baku Mutu Kualitas Air Per Jenis Ikan } \\
\hline & $\begin{array}{c}\text { Sungai } \\
\text { Tabalong }\end{array}$ & $\begin{array}{c}\text { Sungai } \\
\text { Pemayaran }\end{array}$ & Mas & Nila & Patin & Lele \\
\hline Suhu $\left({ }^{\circ} \mathrm{C}\right)$ & 28 & 30 & $25-30$ & $25-30$ & $25-30$ & $25-30$ \\
\hline $\begin{array}{l}\text { Kecerahan } \\
(\mathrm{cm}) \\
\text { Oksigen }\end{array}$ & 28 & 26 & $10-30$ & $40-50$ & $30-50$ & $25-35$ \\
\hline $\begin{array}{l}\text { Terlarut } \\
\text { (DO) } \\
\text { (mg/L) }\end{array}$ & 4,2 & 2 & $>5$ & $>5$ & $>5$ & $>4$ \\
\hline $\begin{array}{l}\text { Derajat } \\
\text { Keasaman } \\
(\mathrm{pH})\end{array}$ & 7 & 7 & $6,5-8,5$ & $6,5-8,5$ & $6,5-8,5$ & $6,5-8,5$ \\
\hline $\begin{array}{l}\text { Amoniak } \\
\left(\mathrm{NH}_{3}\right) \\
(\mathrm{mg} / \mathrm{L})\end{array}$ & 3,33 & 0,25 & $<0,2$ & $<0,2$ & $<0,01$ & $<1$ \\
\hline $\begin{array}{l}\text { Nitrit }\left(\mathrm{NO}_{2}\right) \\
(\mathrm{mg} / \mathrm{L})\end{array}$ & $<0,3$ & $<0,3$ & $<0,06$ & $<0,06$ & $<1$ & $<0,06$ \\
\hline
\end{tabular}

Tabel 5: Kesesuaian Kualitas Air di Kabupaten Tabalong

\begin{tabular}{|c|c|c|c|c|c|c|c|c|}
\hline \multirow{2}{*}{$\begin{array}{c}\text { Kondisi } \\
\text { Kualitas } \\
\text { Air }\end{array}$} & \multicolumn{4}{|c|}{ Sungai Tabalong } & \multicolumn{4}{|c|}{ Sungai Pemayaran } \\
\hline & Mas & Nila & Patin & Lele & Mas & Nila & Patin & Lele \\
\hline Suhu $\left({ }^{\circ} \mathrm{C}\right)$ & $\checkmark$ & $\checkmark$ & $\checkmark$ & $\checkmark$ & $\checkmark$ & $\checkmark$ & $\checkmark$ & $\checkmark$ \\
\hline $\begin{array}{l}\text { Kecerahan } \\
(\mathrm{cm})\end{array}$ & $\checkmark$ & & & $\checkmark$ & $\checkmark$ & & & $\checkmark$ \\
\hline $\begin{array}{l}\text { Oksigen } \\
\text { Terlarut } \\
\text { (DO) } \\
\text { (mg/L) } \\
\text { Derajat }\end{array}$ & & & & $\checkmark$ & & & & \\
\hline $\begin{array}{l}\text { Keasaman } \\
(\mathrm{pH}) \\
\text { Amoniak } \\
\left(\mathrm{NH}_{3}\right) \\
(\mathrm{mg} / \mathrm{L})\end{array}$ & $\checkmark$ & $\checkmark$ & $\checkmark$ & $\checkmark$ & $\checkmark$ & $\checkmark$ & $\checkmark$ & $\checkmark$ \\
\hline $\begin{array}{l}\text { Nitrit } \\
\left(\mathrm{NO}_{2}\right) \\
(\mathrm{mg} / \mathrm{L})\end{array}$ & & & $\checkmark$ & & & & $\checkmark$ & \\
\hline
\end{tabular}

Berdasarkan tabel diatas dapat diketahui bahwa masing-masing jenis ikan yang merupakan komoditas unggulan di Kabupaten Tabalong memiliki kesesuaian yang berbeda-beda untuk setiap kualitas airnya. Untuk kondisi suhu dan derajat keasaman $(\mathrm{pH})$ perairan di Kabupaten Tabalong baik itu Sungai Tabalong maupun Sungai Pemayaran seluruhnya telah sesuai dengan baku mutu kualitas air perikanan seluruh jenis ikan. Lalu untuk kondisi kecerahan baik pada Sungai Tabalong maupun Sungai Pemayaran, sesuai untuk jenis ikan mas dan lele. Kemudian untuk kondisi oksigen terlarut (DO) hanya pada Sungai Tabalong yang sesuai dengan baku mutu yaitu untuk jenis ikan lele. Kondisi kandungan nitrit baik untuk Sungai Tabalong maupun Sungai Pemayaran keduanya sesuai dengan baku mutu untuk jenis ikan patin, serta untuk kondisi amoniak hanya sesuai untuk komoditas ikan lele di Sungai Pemayaran. Khusus untuk kandungan amoniak pada Sungai Tabalong dan Sungai Pemayaran, belum sesuai dengan baku mutu 


\section{Analisis Kesesuaian Kualitas Air Sungai dengan Baku Mutu Air untuk Budidaya Ikan Air}

Tawar di Kabupaten Tabalong

untuk seluruh jenis ikan yang menjadi komoditas unggulan di Kabupaten Tabalong. Kondisi kualitas air yang tidak sesuai disebabkan karena adanya aktivitas industri di hulu perairan Sungai Kabupaten Tabalong. Aktivitas industri ini mengakibatkan terjadinya pencemaran di aliran sungai yang mana merupakan tempat budidaya ikan keramba, sehingga terdapat kondisi kualitas perairan di Kabupaten Tabalong yang tidak sesuai. Meskipun demikian, secara keseluruhan ikan-ikan yang ada masih dapat bertahan hidup dan kegiatan budidaya masih dapat dilakukan. Namun, untuk meminimalisir dan mengatasi permasalahan tersebut agar kondisi kualitas air dapat sesuai dengan baku mutu yang telah ditetapkan, dibutuhkan upaya pengendalian kegiatan di area sungai yang boleh dan tidak boleh dilakukan melalui regulasi, serta penerapan teknologi aquaculture untuk meningkatkan mutu kualitas air.

\section{Kesimpulan}

Kondisi suhu dan derajat keasaman $(\mathrm{pH})$ di perairan Sungai Tabalong dan Sungai Pemayaran telah sesuai. Berbeda dengan kondisi kecerahan di Sungai Tabalong dan Sungai Pemayaran dimana hanya komuditas ikan mas dan lele yang sesuai dengan baku mutu. Hal ini juga terjadi pada indikator nitrit $\left(\mathrm{NO}_{2}\right)$ di Sungai Tabalong dan Sungai Pemayaran yang dimana komoditas ikan yang sesuai hanya jenis ikan patin. Sedangkan untuk indikator kondisi oksigen terlarut (DO) yang memiliki kesesuaian hanya di Sungai Tabalong untuk komoditas jenis ikan patin, serta untuk indikator amoniak $\left(\mathrm{NH}_{2}\right)$ kesesuaian hanya di Sungai Pemayaran untuk komoditas ikan lele. Meskipun demikian, secara keseluruhan ikanikan yang ada masih dapat bertahan hidup dan kegiatan budidaya masih dapat dilakukan, namun dibutuhkan upaya pengendalian kegiatan di area sungai dan penerapan teknologi aquaculture agar kualitas air dapat meningkat dan optimal untuk lingkungan hidup komoditas ikan-ikan yang ada.

\section{References}

Astrijaya, S., Andi Agussalim dan Mohammad Rasyid Ridho. (2015) 'Akurasi Nilai Konsentrasi Klorofil-a dan Suhu Permukaan Laut Menggunakan Data Penginderaan Jauh di Perairan Pulau Alanggantang Taman Nasional Sembilang' Jurnal. FMIPA. Universitas Sriwijaya.

Balai Besar Budidaya Perikanan Air Tawar (2016), 'Baku Mutu Air untuk Budidaya Ikan', Sukabumi: Balai Besar Budidaya Perikanan Air Tawar.

Emilia, Ita, (2019) 'Analisa Kandungan Nitrat Dan Nitrit Dalam Air Minum Isi Ulang Menggunakan Metode Spektrofotometri Uv-Vis', Jurnal Indobiosains. Vol 1. No. 1: 38-44

Hamuna, Rosye H.R. Tanjung, Suwito, Hendra K. Maury dan Alianto, (2018) 'Kajian Kualitas Air Laut dan Indeks Pencemaran Berdasarkan Parameter Fisika-Kimia Di Perairan Distrik Depapre, Jayapura' Program Studi Ilmu Lingkungan Sekolah Pascasarjana, Universitas Diponegoro

Hibban Muhamad, Arya Rezagama, Purwono(2016), 'Studi Penurunan Konsentrasi Amonia Dalam Limbah Cair Domestik Dengan Teknologi Biofilter Aerobmedia Tubular Plastik Pada Awal Pengolahan', Jurnal Teknik Lingkungan, Vol 5, No.2

Pemerintah Daerah Kabupaten Tabalong. (2014), 'Rencana Tata Ruang Wilayah Kabupaten Tabalong Tahun 2014-2034'. Tabalong: Pemerintah Daerah Kabupaten Tabalong.

Putra S, M. Kelana. (2007), 'Rancangan Bangunan dan Analisa Perpindahan Panas pada Ketel Uap Bertenaga Listrik'. Medan: USU.

Sugianti ayuk, Lismining Pujiyani Astuti, (2018), 'Respon Oksigen Terlarut Terhadap Pencemaran Dan Pengaruhnya Terhadap Keberadaan Sumber Daya Ikan Di Sungai Citarum', Balai riset perikanan Kementerian Kelautan dan Perikanan, Jakarta. Vol 19. No 02: 3-4 
Analisis Kesesuaian Kualitas Air Sungai dengan Baku Mutu Air untuk Budidaya Ikan Air Tawar di Kabupaten Tabalong

Susiana, Niartiningsih Andi , Amran Muh. Anshar, (2017) 'Hubungan Antara Kesesuaian Kualitas Perairan Dan Kelimpahan Kima (Tridacnidae) Di Kepulauan Spermonde', Fakultas Ilmu Kelautan dan Perikanan Universitas Hasanuddin, Makassar

Yanti, Novita Dwi (2016), 'Penilaian Kondisi Keasaman Perairan Pesisir Dan Laut Kabupaten Pangkajene Kepulauan Pada Musim Peralihan I', Program Studi Ilmu Kelautan Departemen Ilmu Kelautan Fakultas Ilmu Kelautan Dan Perikanan Universitas Hasanuddin, Makassar 